\title{
Recurrent acute retrograde intragastric intussusception
}

\author{
J. ALEXANDER WILliamS AND J. F. FIELDING \\ From the General Hospital, Birmingham
}

SUMMARY A case of recurrent acute retrograde jejunogastric intussusception is described in a 45-year-old man who five years previously had had an antecolic gastrojejunostomy.

Two previous haematemases imply that this complication was recurrent and self reducing an unusual and fortuitous outcome.

Awareness of the possibility of acute intussusception following gastroenterostomy or partial gastrectomy is stressed.

Wolfler is credited with the first gastroenterostomy in 1881 (Caudell and Lee, 1955). It was nearly 25 years later before the complication of retrograde intragastric intussusception was reported (Bozzi, 1914; Steber, 1917). The first authoritative review appeared in the New England Journal of Medicine in 1928 (White and Jankelson) and many case reports have been documented since then, so that 111 such patients had been reported by the time Conklin and Marlowitz (1965) added three patients in a recent comprehensive review.

Whilst chronic recurrent retrograde intragastric intussusception is being increasingly recognized (Caudell and Lee, 1955), recurrent acute intussusception with bleeding does not seem to have been previously reported.

\section{Case Report}

J.N., a 45-year-old Irishman, was admitted to this hospital on 1 February 1970 . He had had a gastroenterostomy performed for duodenal ulceration in November 1964. On 19 July 1969 he was admitted to another hospital with a 24-hour history of severe epigastric pain followed by haematemesis. On admission the notes recorded a pulse of 80 per minute and a blood Received for publication 19 March 1970. pressure of $115 / 90 \mathrm{~mm} \mathrm{Hg}$. A mass was palpable in the epigastrium. He was transfused with 4 pints of blood and the pain subsided. His subsequent stay in hospital was uneventful and he was discharged home on 29 July. A barium meal was performed on 12 August and showed a normally functioning gastroenterostomy (Fig. 1). In September 1969 the patient had a further episode of epigastric pain and haematemesis which was again treated conservatively without admission to hospital.

On the morning of the present admission the patient experienced a 'searing' epigastric pain followed by a haematemesis. He looked pale and ill; the pulse was 78 , regular, and the blood pressure $120 / 70 \mathrm{~mm} \mathrm{Hg}$. In the abdomen there was the scar of previous operation and a poorly defined mass was palpable in the epigastrium and left hypochondrium. Rectal examination revealed normal faeces. The haemoglobin was 12.6 $\mathrm{g} / 100 \mathrm{ml}$. A barium meal (Figs. 2 and 3) showed the presence of a large retrograde jejunogastric intussusception. The patient was transfused with 2 pints of blood before operation.

At operation a retrograde intussusception of the efferent loop of jejunum into the stomach was confirmed. The patient had had an antecolic gastrojejunal anastomosis. No ulcer was seen at the stoma or in the duodenum and no enteroanastomosis had been performed. The intussusception was not reducible and $65 \mathrm{~cm}$ of intus- 


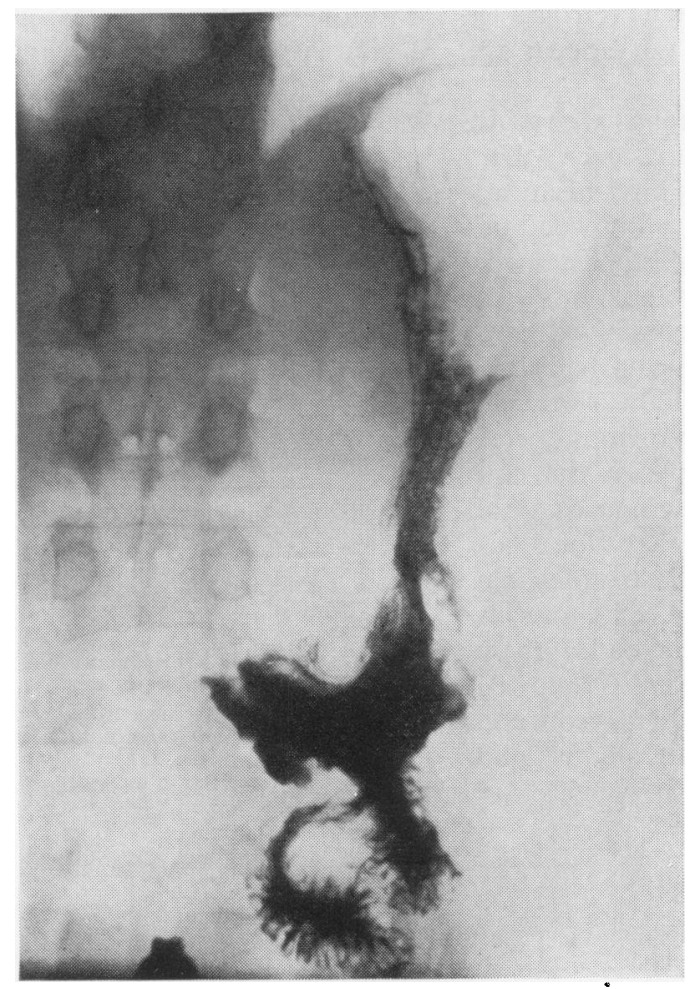

Fig. 1 August 1969: normally functioning gastroenterostomy.

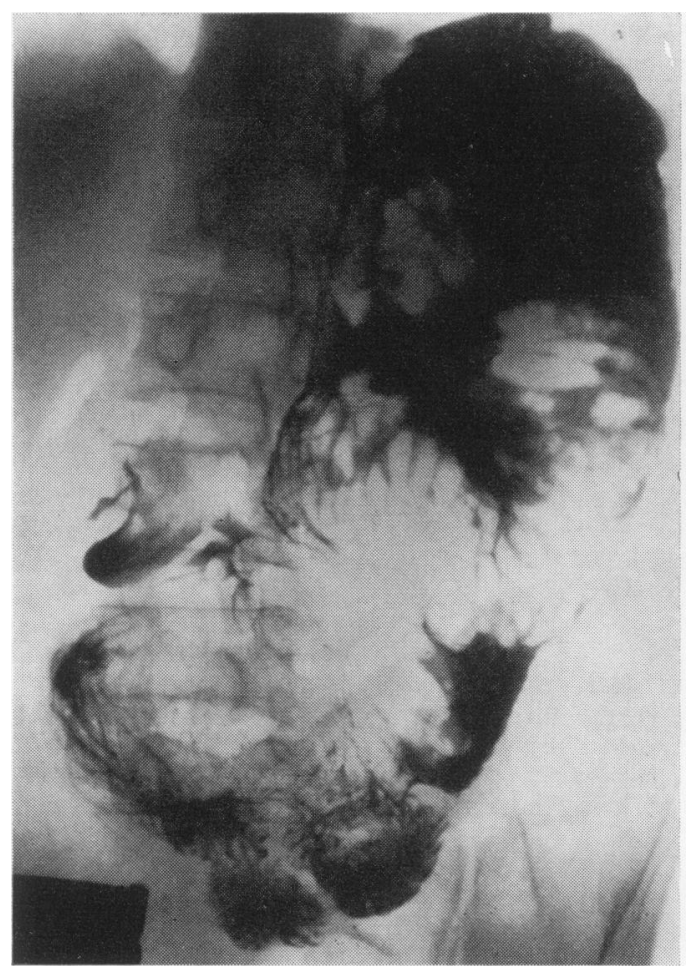

suscepted bowel had to be resected. The gastroenterostomy was closed and the continuity of the bowel restored. A vagotomy and pyloroplasty were performed. The postoperative course was uneventful, and the patient was discharged to convalescence on 11 February 1970 . He has been reviewed since and remains well.

\section{Discussion}

Acute retrograde jejunogastric intussusception is a serious complication of gastroenterostomy or partial gastrectomy (Lawson and Whitener, 1950). Eighty-four of the 114 cases reviewed by Conklin and Marklowitz (1965) occurred following gastroenterostomy and 30 after partial gastrectomy. Of the patients who had had a gastroenterostomy, 56 had a retrocolic anastomosis, 12 an antecolic anastomosis, and the nature of the anastomosis was unstated in 14.

The mortality on conservative therapy is high; death occurred in $15(83 \%)$ of the 17 postgastroenterostomy patients so treated. As haematemasis implies venous engorgement in the intussuscepted bowel, and thus self reduction is unlikely, it is remarkable that this patient survived two episodes of bleeding. Spontaneous reduction following haematemesis must be uncommon so

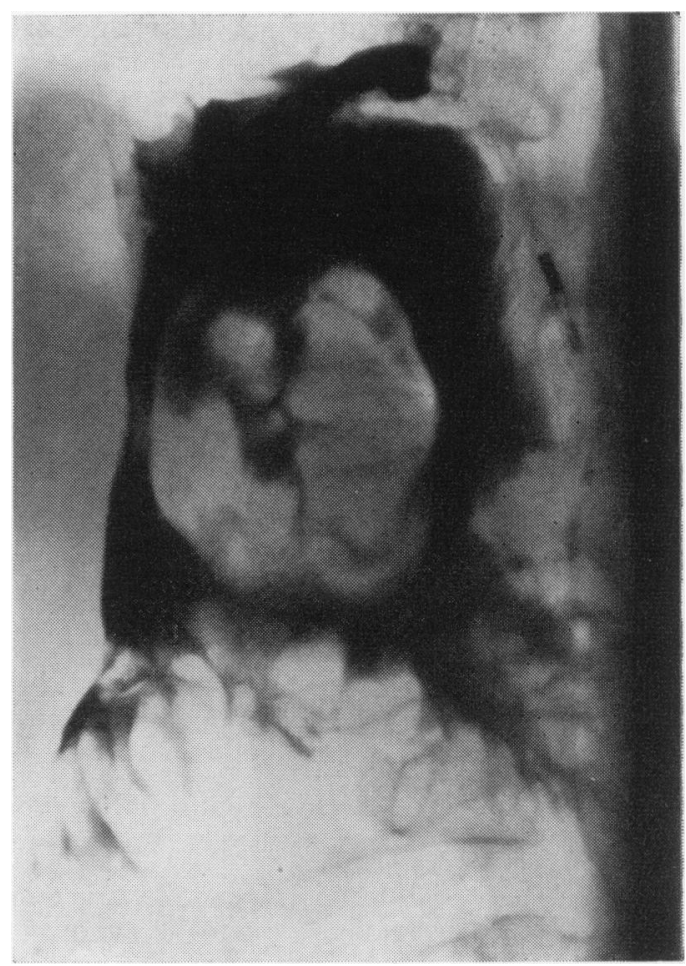

Fig. 3 February 1970: head of the intussusceptum.

Fig. 2 February 1970: large retrograde jejunovalvulae conniventes. 
it is not surprising that recurrent acute retrograde intragastric intussusception does not appear to have been reported before.

The most obvious aid to diagnosis of this condition is awareness of its existence. The characteristic history is one of short duration, severe, colicky epigastric pain, followed by vomiting which may not initially be bloodstained. On examination the patient may look more ill than the short history suggests, possibly due to gastric distension and fluid and electrolyte loss, in addition to blood loss. There will be a surgical scar in the abdomen indicating a previous operation and a mass may be palpable in the epigastrium. There may be a normal coloured stool on rectal examination suggesting that blood has not been passed on down the gastrointestinal tract. It is important, once the diagnosis is suspected, to have radiographs taken of these patients without delay as early surgery is followed by a mortality of between $10.5 \%$ (Lawson and Whitener, 1950) and $18.3 \%$ (Conklin and
Marklowitz, 1965), whereas surgery more than 48 hours from the onset of symptoms is associated with a $46.2 \%$ mortality rate (Lawson and Whitener, 1950).

We should like to thank Dr W. T. Cooke for permission to report this case.

\section{References}

Bozzi, E. (1914). Boll. Accad. med. (Genova), 3-4, 122.

Caudell, W. S., and Lee, C. M., Jr. (1955). Acute and chronic jejunogastric intussusception. New Engl. J. Med., 253, 635-640.

Conklin, E. F., and Markowitz, A. M. (1965). Intussusception, a complication of gastric surgery. Surgery, 57, 480-488.

Lawson, E. H., and Whitener, D. L. (1950). Retrograde jejunogastric intussusception: report of a case. Arch. Surg., 60, 242-246.

Steber (1917). Ueber einen seltenen Fall von Invaginations-Ileus. Munch. med. Wschr., 64, 648-649.

White, F. W., and Jankelson, I. R. (1928). Late intussusception of bowel into the stomach after gastro-enterostomy. New Engl. J. Med., 199, 1189-1193.

\section{The September 1970 Issue}

\section{THE SEPTEMBER 1970 ISSUE CONTAINS THE FOLLOWING PAPERS}

Intestinal mucosal uptake of iron and iron retention in idiopathic haemochromatosis as evidence for a mucosal abnormality $L$. $W$. POWELL, C. B. CAMPBELL, AND ELIZABETH WILSON

The formation of iron complexes with bile and bile constituents A. JACOBS AND P. M. MILES

Pyloric regurgitation and gastric ulcer F. J. FLINT AND P. GRECH

Oesophageal reflux and gastric secretion A. S. WARD

A case of small-intestinal mucosal atrophy R. E. BARRY, JOHN S. MORRIS, AND A. E. A. READ

Arthropathy, ankylosing spondylitis, and clubbing of fingers in ulcerative colitis K. N. JALAN, R. J. PRESCOTT, R. J. WALKER, W. SIRCUS, J. P. A. MCMANUS, AND W. I. CARD

Portal hypertension and bleeding ileal varices after colectomy and ileostomy for chronic ulcerative colitis A. D. CAMERON AND D. J. FONE

Ulcerative colitis in the South African Bantu J. D. SOBEL AND L. SCHAMROTH

Intestinal pseudo-obstruction in systemic amyloidosis DAVID A. LEGGE, ERIC E. WOLLAEGER, AND HARLEY C. CARLSON
Effect of glycine and glucose on sodium and water absorption in patients with cholera D. R. NALIN, R. A. CASH, M. RAHMAN, AND MD. YUNUS

Personality pattern and emotional stress in the genesis of gastric ulcer M. H. ALP, J. H. COURT, AND A. KERR GRANT

Radiological diagnosis of recurrent colonic carcinoma at the anastomosis CLIVE BARTRAM AND JOHN E. HALE

Ultrastructural study of two cases of $a$-chain disease JACQUES SCOTTO, HÉLÈNE STRALIN, AND JACQUES CAROLI with the technical assistance of MONIQUE GEGOU

Vagotomy and gallbladder function STIG FAGERBERG, SVEN GREVSTEN, HENRY JOHANSSON, AND URBAN KRAUSE

\section{Technique}

A technique for assessing pyloric reflux PAUL GRECH

Progress report

ABO blood groups and gastrointestinal function M. J. S. LANGMAN

\section{Progress report}

The vagus, the bile, and gallstones I. A. D. BOUCHIER

Notes and activities 